\title{
Convergências entre a abordagem centrada na pessoa e Sören Kierkegaard
}

\section{Convergences between person-centered approach and Sören Kierkegaard}

\author{
Francisco Pablo Huascar Aragão Pinheiro ${ }^{[a]}$, Emanuel Meireles Vieira $^{[b]}$
}

[a] Mestre em Psicologia, psicólogo do Departamento de Desenvolvimento Humano da Universidade Federal do Ceará.

[b] Mestre em Psicologia, professor da Faculdade de Psicologia da Universidade Federal do Pará, Belém - Pará, e-mail: emeireles@ufpa.br

\section{Resumo}

O artigo discute convergências epistemológicas existentes entre a Abordagem Centrada na Pessoa (ACP), de Carl Rogers, e a filosofia de Sören Kierkegaard. A escolha de Kierkegaard para travar esses questionamentos se justifica por sua relevância na história da filosofia e por Rogers reconhecer o alinhamento entre suas ideias e algumas concepções existentes no pensamento deste filósofo. Ao longo do debate sobre os pressupostos que fundamentam os procedimentos metodológicos da ACP, são apresentadas as noções de cientista e de pessoa, que representam modos distintos de conceber a produção de conhecimento. Admitem-se tais concepções como conflitantes: a primeira se aproxima do ideário da ciência moderna, para o qual a implicação subjetiva é rechaçada, e a segunda se avizinha de uma postura existencialista, na qual é possível produzir conhecimento pela via da sensibilidade. A partir da noção de pessoa são debatidos aspectos da perspectiva rogeriana que se alinham com questões concernentes ao pensamento kierkegaardiano, destacando-se: 1) a afirmação de que o conhecimento advém de uma interação direta com a experiência; 2) a pressuposição de uma unidade, uma não dualidade entre o sujeito e o objeto; 3 ) a admissão da fluidez da existência, o que implica aceitar a racionalidade como incapaz de abarcar todas as facetas da realidade; e 4) a concepção de que o conhecimento se produz individual e singularmente, de modo que as inteligibilidades produzidas a partir da relação estabelecida com a experiência são incomunicáveis. Ressalte-se que algumas dessas aproximações foram aludidas por Rogers; outras, no entanto, são apontadas pelos autores deste trabalho.

Palavras-chave: Abordagem centrada na pessoa. Kierkegaard. Epistemologia.

\section{Abstract}

The paper discusses epistemological convergences between Person-Centered Approach, by Carl Rogers, and the philosophy of Sören Kierkegaard. Kierkegaard was chosen to deal with this issues because of his importance in the history of philosophy and also because Rogers recognizes the approach between its propositions and some conceptions 
of this philosopher. The notions of scientist and person are presented in the debate about the assumptions underlying the methodological procedures of the PCA. It is admitted that these concepts are conflicting: the first one approaches the concepts of modern science, which denies the subjective involvement; the second one follows an existentialist approach, which believes that knowledge can be produced by means of sensitivity. The concepts of Carl Rogers that has to do with the Kierkegaad's philosophy are discussed from the concept of person. The following issues are highlighted: 1) the claim that knowledge comes from a direct interaction with the experience; 2) the assumption of a unit between subject and object; 3) the admission that that rationality fails to capture all facets of reality because of its constant flux; 4) the knowledge produced taking into account the ideas presented is considered unreachable. It must be highlighted that some of this issues were pointed by Carl Rogers. On the other hand, other questions were indicated by the authors of this article.

Keywords: Person-centered approach. Kierkegaard. Epistemology.

Discussões epistemológicas são alvo da preocupação de cientistas e filósofos (Bachelard, 1971). Ambos têm arrogado para si as competências necessárias para travar este debate, enquanto há quem aposte numa relação interdisciplinar. Vê-se que circunscrever esse campo e delimitar suas especificidades é tarefa controversa (Bombassaro, 1992).

$\mathrm{O}$ interesse epistemológico em torno das teorias da Psicologia é alvo de producões nas mais diversas áreas que constituem essa disciplina. A Abordagem Centrada na Pessoa (ACP), graças a seu amplo alcance e repercussão, desenvolve em seu bojo um profundo debate a respeito das concepções subjacentes a seus construtos teórico-metodológicos (Amatuzzi, 1989, 2001; Moreira, 2007; Fonseca, 1998; Cury, 1987).

Ao longo de sua obra, Rogers, contudo, não se ateve de modo exaustivo a debates sobre filosofia da ciência, termo utilizado pelo autor, a despeito das controvérsias sobre a distinção deste em relação a definições sobre a epistemologia (Blanché, 1988). Tal tema é notado em poucas publicações dispersas. Apenas em uma obra completa (Rogers \& Coulson, 1973), o criador da ACP expõe essa discussão de maneira pormenorizada. Apresentar-se-ão a seguir interpretações que se configuram como possibilidades de compreensão acerca de um pensamento extremante criativo como o rogeriano.

Este artigo parte, portanto, de uma pergunta ampla: quais os pressupostos implicados com o(s) modo(s) de produção de conhecimento presentes na obra rogeriana? Porém, tendo em vista a amplitude da questão, faz-se necessário estabelecer um parâmetro mais específico para essa discussão.
Tomar-se-ão como referência para dar inteligibilidade a alguns desses pressupostos as convergências epistemológicas existentes entre a ACP e a filosofia de Sören Kierkegaard.

A escolha da filosofia kierkegaardiana como parâmetro deve-se a dois fatores. O primeiro diz respeito à relevância de Kierkegaard na história da filosofia. De origem protestante, esse filósofo dinamarquês rompeu com a Igreja Luterana e desenvolveu um modo singular de compreender a relação entre o indivíduo e a divindade, estabelecendo um forte contraponto à perspectiva hegeliana (Farago, 2006). Também é relevante ressaltar que são atribuídas a Kierkegaard as ideias seminais do existencialismo formulado no século XX (Sartre, 1979).

O segundo fator diz respeito ao reconhecimento expresso pelo próprio Rogers em relação ao alinhamento entre suas ideias e algumas concepções existentes no pensamento de Kierkegaard (Moreira, 2009). O autor adverte, porém, que nunca foi um estudioso do existencialismo e que viu nesse filósofo não um fundamento, mas alguém cujas ideias se assemelhavam às suas. Afirma Rogers (1961/2001, p. 227): "não estudei filosofia existencial [...] Embora houvesse em Kierkegaard [...] muitos pontos que para mim não significavam nada, havia e há [...] intuições e convicções profundas que exprimem perfeitamente perspectivas que eu tinha mas que não conseguira formular".

Ao longo deste artigo tentar-se-á delimitar o modo como estas intuições e convicções repercutem epistemologicamente na perspectiva desenvolvida por Rogers. Ressalte-se que algumas dessas aproximações foram aludidas por Rogers (Rogers, 1961/2001; Evans, 1979); outras, no entanto, são apontadas pelos autores deste artigo. 


\section{Posturas epistemológicas na ACP}

Fazendo um rápido apanhado dos questionamentos epistemológicos levantados por Rogers ao longo de sua obra, observa-se que no livro Tornar-se pessoa há uma unidade dedicada à discussão acerca da filosofia da ciência psicológica. Em $O$ homem e a ciência do homem, publicado em 1968, juntamente com William Coulson, Rogers edita duas semanas de debates sobre Filosofia da Ciência. Tais questionamentos se deram num seminário nos Estados Unidos, do qual participaram filósofos, biólogos, psicólogos e professores universitários.

O arcabouço ético e epistemológico da Psicologia é amplamente debatido nesse livro pelas diversas áreas representadas. Dentre os questionamentos que orientam a discussão desenvolvida por Rogers (Rogers \& Coulson, 1973, p. 56) colocam-se os seguintes: "como adquirimos o conhecimento? $\mathrm{O}$ que é 'verdadeiro'? Quais são as características identificadoras de um cientista? O que é ciência? Qual a natureza específica da ciência do comportamento?”.

Ao tomarmos essas perguntas para visar a historicamente o pensamento de Rogers, observamos que suas formações, acadêmica e profissional, fizeram-no se relacionar com dois posicionamentos epistemológicos que conviveram em seu pensamento durante vários anos de sua carreira. Kinget (Rogers \& Kinget, 1977) aponta tais posicionamentos: por um lado, uma perspectiva especulativa oriunda da psicanálise norte-americana, e em outra direção, uma orientação empírica inspirada no pragmatista norte-americano John Dewey (Cavalcante Júnior \& Sousa, 2008). Kinget (Rogers \& Kinget, 1977, p. 24) destaca ainda uma inclinação de Rogers rumo às ciências naturais, fato que o levava a "voltar-se para a observação e os dados da experiência, mais que para as teorias e especulações".

Talinclinação encaminhou o criador da ACP a ser um dos primeiros psicólogos a utilizar o registro de sessões de psicoterapia em gravações de áudio e vídeo, para fins de pesquisa. Segundo Evans (1979, p. 30), este fato será relevante, pois torna Rogers "o primeiro pesquisador científico da psicoterapia [...] Ele insistiu em afirmar [...] que os fenômenos, aparentemente indevassáveis, da mudança pessoal, poderiam ser estudados com métodos científicos de investigação controlada". Nesse sentido, Rogers (Rogers \& Rosenberg, 1986, p. 30) compreendia que seu trabalho "tornou possível o estudo empírico de fenômenos bastante subjetivos".

A experiência como psicoterapeuta, por outro lado, direciona Rogers a descrever a terapia como uma "experiência viva", de tal forma que os métodos usualmente correntes para investigação em Psicologia, apesar de úteis, não conseguiriam captá-la plenamente. Conforme indica o autor: "em minha opinião, o cálido, subjetivo e humano encontro de duas pessoas é mais eficaz para facilitar mudanças do que a mais precisa combinação de técnicas provenientes da teoria do aprendizado ou do condicionamento operante" (Rogers, 1980, p. 106).

O posicionamento entre a experiência imediatamente vivenciada na psicoterapia e o método científico instaura em Rogers um paradoxo. Por um lado, ele era um cientista que registrava e analisava com a máxima precisão os fenômenos presentes numa situação até então não investigada de modo experimental, qual seja, a psicoterapia. Por outro, a investigação desse fenômeno por métodos considerados científicos mostrou-lhe a necessidade da implicação subjetiva do terapeuta durante seu trabalho (Rogers \& Stevens, 1976) e que, por meio dessa implicação, também era possível destacar certa inteligibilidade do processo.

A experiência clínica rogeriana evidenciou a possibilidade de produzir conhecimento pela via da sensibilidade. A aproximação dessa forma de conhecer é descrita por Rogers (1961/2001, p. 228229) do seguinte modo:

quanto melhor terapeuta me tornava [...] mais consciência ganhava da minha completa subjetividade quando exercia melhor essa função. Mas, ao tornar-me melhor investigador, mais teimoso e mais científico [...], sentia um embaraço crescente perante a distância entre a minha objetividade rigorosa como cientista e a minha subjetividade quase mística como terapeuta.

Esse posicionamento, que aponta para a implicação subjetiva do terapeuta, vai de encontro à racionalidade originada na revolução científica do século XIV e desenvolvida pelas ciências naturais. Tal racionalidade, tornada hegemônica no século XIX, desconfia das evidências imediatas da percepção; separa o homem da natureza, estabelecendo uma clara distinção entre sujeito e objeto; aposta 
na experimentação como ferramenta metodológica; toma a matemática como a linguagem, o modelo de análise e a forma privilegiada de representação da matéria; admite ainda que, diante da complexidade da natureza, é preciso dividir e classificar os fenômenos para, em seguida, estabelecer relações de causa e efeito (Santos, 1988).

Aniquilam-se, portanto, as escolhas idiossincráticas do indivíduo que conhece. A subjetividade, por conseguinte, é um empecilho a ser superado com a correta utilização do método. A certeza, num projeto moderno de Ciência, não se dá pela via da sensação, mas sim pelas evidências que a realidade fornece, a qual, por esse ponto de vista, pode e deve ser desvelada (Figueiredo, 1992).

Para Rogers, entretanto, é possível que a verdade passe por um crivo que não encontra correspondência objetiva: a experiência subjetiva. $\mathrm{O}$ autor aponta para a não exclusividade da ciência moderna como forma de construção do conhecimento e, assim, cria um embaraço para si mesmo. A esse respeito, considera conflitantes as duas funções que desempenharia: a de cientista, que investiga os fenômenos da psicoterapia, e a de pessoa, que se relaciona com os clientes.

Essa querela é explicitada no artigo "Pessoa ou ciência? Um problema filosófico". Em termos epistemológicos, Rogers (1961/ 2001,p. 228) se refere àquelas duas posições do seguinte modo: "tratava-se de uma oposição entre o positivismo lógico em que eu fora educado e pelo qual tinha um profundo respeito e um pensamento existencial orientado subjetivamente que crescia em mim, porque me parecia adequar-se [...] à minha experiência terapêutica”.

Rogers, como cientista, via a necessidade de investigação minuciosa do processo terapêutico. Ressaltava a influência que recebeu da psicologia norte-americana graças à "sua capacidade para dar definições operacionais, para a mensuração objetiva, a insistência no método científico e a necessidade de submeter todas as hipóteses a um processo objetivo de verificação ou de refutação" (Rogers, 1974, p. 18). A terapia, como qualquer fenômeno natural, estaria submetida a relações de causalidade, explicitáveis em sentenças "se-então" (Rogers, 1994). A ciência teria como finalidade "trabalhar para uma compreensão dos fenômenos [...] isto significa conhecimento objetivo dos acontecimentos e das relações funcionais entre estes mesmos acontecimentos" (Rogers, 1961/2001, p. 235).
Entretanto, como pessoa envolvida na relação terapêutica, o autor identificou outra forma de proceder, na qual a implicação do investigador no processo seria fundamental. Segundo Rogers (1961/2001, p. 242-243), "O desenvolvimento da ciência num domínio como o da terapia, ou é irrelevante para a experiência, ou pode, de fato, tornar mais difícil viver a relação como um acontecimento pessoal, vivencial".

Como se pode perceber na passagem mencionada, na psicoterapia, um modo distanciado de lidar com a experiência impede que o terapeuta se implique com a situação vivenciada, afastando-o do momento em que esta ocorre. Ainda a este respeito, Rogers (Rogers \& Stevens, 1976, p. 218) assinala: "na medida em que estamos pensando teoricamente na relação, tornamo-nos espectadores e não-participantes - e é como participantes que somos eficientes". O envolvimento do terapeuta com o outro se torna, portanto, fator preponderante para o sucesso do processo psicoterápico, bem como uma ferramenta para produção de conhecimento. Isso significa deixar de lado, no momento da relação, a atitude distanciada do fazer científico tradicional.

Para Rogers, os sentidos se constituem como uma via privilegiada de acesso à realidade por meio da valorização da sabedoria inerente ao organismo. Ao discorrer sobre tal modalidade de conhecimento, Rogers (Rogers \& Coulson, 1973, p. 61) utiliza-se de uma comparação entre o cientista e o artista: este último "confia em si próprio e em sua experiência [...] 'é amigo' de si próprio, na medida em que procura pelas noções de verdade que lhe são próprias, que realmente lhe pertencem, que constituem sua base para dar o salto subjetivo". Essa posição é avessa à adotada pela sociedade moderna, para a qual a razão é o parâmetro de julgamento acerca da veracidade e do rigor do conhecimento (Figueiredo, 2004).

Rogers, ao longo de sua obra, tentou conciliar essas duas posições, a de pessoa e a de cientista. Chegou a reformular seu entendimento sobre a ciência, afirmando que "todo o conhecimento, inclusive todo o conhecimento científico, é uma imensa pirâmide invertida que repousa sobre esta minúscula base subjetiva e pessoal" (Rogers \& Coulson, 1973, p. 60-61).

Ao final da carreira, Rogers parecia compelido a abandonar um modelo restrito de ciência e a ter uma compreensão diferenciada sobre as tentativas 
de produzir conhecimento. Percebia, a partir dos avanços da física e da biologia, que a ideia linear de causa e efeito era superada por uma perspectiva da ciência da complexidade, para a qual os eventos do universo encontram-se intrinsecamente relacionados (Rogers, Wood, O’hara, \& Fonseca, 1983). Nas palavras do autor:

...fui influenciado pela noção geral de modelo científico, levantamento de hipóteses, teste de hipóteses, e assim por diante. Acho que esse aspecto foi muito importante na minha vida ainda que, atualmente, sinto-me pronto a deixar esse tipo de ciência para trás. Não quero abandonar nada da operacionalização cuidadosa, mas já é tempo desenvolvermos um novo tipo de ciência humana que, provavelmente, será bem diferente dos estudos empíricos feitos no passado (Evans, 1979, p. 119).

Outra forma de fazer ciência, praticada pelo próprio Rogers, pode ser entendida a partir de convergências de seu pensamento com o modo existencial de compreensão da realidade. Desse modo, apresentar-se-á a seguir uma série de elementos que aproximam aspectos do pensamento rogeriano das ideias de Sören Kierkeggard.

\section{Convergências epistemológicas entre os pensamentos de Rogers e Kierkegaard}

Podem ser observadas convergências epistemológicas entre características depreendidas do posicionamento associado à noção de pessoa, em Rogers, e a filosofia existencial de Kierkegaard. Dentre estas características, destacam-se: 1) a afirmação de que o ato de conhecer se dá a partir de uma interação direta com a experiência; 2) a pressuposição de uma unidade, uma não dualidade entre o sujeito e o objeto; 3) a admissão do devir e da fluidez da existência, o que implica aceitar a racionalidade como incapaz de abarcar todas as facetas da realidade; e 4) a concepção da produção do conhecimento como individual e singular, de modo que as inteligibilidades produzidas a partir da relação estabelecida com a experiência são incomunicáveis.

Tratando do primeiro aspecto ora levantado, observa-se que, ao terapeuta que se posiciona como pessoa, caberia mergulhar no relacionamento terapêutico e colocar-se sensível a ele: "a terapia é uma experiência do eu, não sobre o eu. A compreensão intelectual não basta” (Rogers \& Wood, 1978, p. 199). O terapeuta, portanto, não toma o cliente como um objeto de conhecimento, mas entra em uma corrente de experiência que conduz o processo. Experiência que não está subordinada à consciência ou a um aparato cognitivo, mas baseada na sensibilidade total do organismo. Rogers (1961/2001, p. 231) afirmava não ter consciência sobre o caminho tomado pelas relações estabelecidas na psicoterapia. Segundo ele, “... é como se nós dois, o cliente e eu, nos deixássemos deslizar, muitas vezes com receio, para a corrente do devir, uma corrente ou processo que nos arrasta".

Quando isso ocorre, parece haver uma unidade entre as vivências do terapeuta e do cliente, mas sem garantias de que surgirá algum entendimento sobre assuntos ou questões específicos. Decorrem daí compreensões sobre a experiência que não possuem uma determinação objetiva. No diálogo que Rogers travou com Martin Buber, em 1959, o psicólogo afirma: "eu sinto que quando estou sendo efetivo como terapeuta, eu entro na relação como uma pessoa subjetiva, não como um escrutinador, não como um cientista... quando sou mais efetivo, então de alguma forma, estou relativamente inteiro naquela relação" (Lima, 2008, p. 236).

Esse processo é descrito como uma aprendizagem significativa que surgiria de uma descoberta "auto-apropriada" ocorrida na singularidade do experienciar. Os momentos em que ocorre esse tipo de aprendizagem se assemelham "à descoberta da criança que sabe que 'dois e dois são quatro' e que um dia, brincando com dois objetos e mais dois objetos, apercebe-se subitamente na experiência de uma descoberta absolutamente inédita, que 'dois e dois realmente são quatro”’ (Rogers, 1961/2001, p. 233).

A percepção de Rogers de que o conhecer se dá a partir de uma relação íntima com a experiência pode ser compreendida tomando por base o caráter empírico que concerne à perspectiva existencial. Kierkegaard, na sua discussão sobre o cristianismo, dá algumas indicações que ajudam a compreender este empirismo.

Entre as ideias desse filósofo, é relevante a concepção de que a verdade não está dada a priori e o acesso a esta só surge na medida em que Deus dá a condição para que se possa encontrá-la. "Assim é o discípulo que está ciente de que, sem a condição, nada 
teria visto, já que a primeira coisa que compreendeu foi que ele mesmo era a não verdade" (Kierkegaard, 1844/1995, p. 95). A condição a que o autor alude é o paradoxo da encarnação divina no homem.

A relação do homem com a verdade divina em sua profundidade não se dá a partir do testemunho contemporâneo do Deus encarnado, da apreciação histórica de sua doutrina ou de seus atos, ou mesmo da contemplação de sua representação. Esta ideia ganha substância na seguinte cena descrita por Kierkegaard (1849/1979, p. 249):

E ainda o cômico infinito desse discursador, que, com a verdade do acento e do gesto, comovendo-se, comovendo-te, te faz calafrios pela sua pintura da verdade, e desafia todas as forças do mal e do inferno, com um aprumo de atitude, um topete no olhar, uma justeza do passo, perfeitamente admiráveis - e, cômico infinito, que ele possa quase logo, ainda com quase toda a sua atitude, escapulir-se como um covarde ao mais pequeno incidente!

Como se pode apreender dessa passagem, a falação vazia não se sustenta como acesso mesmo à verdade. Tal qual a cena mostra, a força do discurso meramente intelectualizado sucumbe à menor das provações. O discípulo se constitui verdadeiramente a partir da relação apaixonada (fé) que estabelece com o paradoxo da encarnação: do infinito que se faz finito no homem comum e humilde; do eterno que entra no temporal, na brevidade do instante. Este paradoxo se afirma a tal ponto que resiste à razão. Citando Kierkegaard (1979, p. 91), "esta relação não se deixa exprimir fabulando ou trombeteando, mas somente naquela paixão feliz a que chamamos fé, cujo objeto é o paradoxo, mas o paradoxo une justamente a contradição, é a eternização do histórico e a historização da eternidade".

Assim, Deus, para Kierkegaard, não se dá a conhecer a partir de um conceito. A implicação epistemológica que pode ser compreendida disso é de que a verdade não se produz a partir de um caráter especulativo, mas das ações significativas que ocorrem na relação com a experiência, nesse sentido, um empirismo. Gardiner (2001, p. 100) diz:

[Kierkegaard] sustentava ser uma ilusão supor que todos os aspectos da vida e da experiência humanas pudessem ser acomodados dentro do tipo de perspectiva possibilitado pelos modos de pensamento distanciado e observacional... Ele procura enfatizar o abismo profundo que separa duas posturas possíveis de adotar em nossos relacionamentos com a realidade $-\mathrm{a}$ postura distanciada de contemplação e pesquisa objetiva e a postura engajada e participativa de volições práticas.

Por esse viés, é possível compreender a aprendizagem significativa tratada por Rogers (1978), na qual, como dito alhures, o conhecimento surge de uma implicação com e na experiência e não a partir de um distanciamento em relação a esta. Afirma-se um empirismo que traz um primeiro alinhamento entre os posicionamentos de Rogers e Kierkegaard. Para o terapeuta que se posiciona como pessoa, portanto, o processo psicoterapêutico não deve ser pensado, mas vivido. Holanda (1997, p. 121) diz o seguinte a esse respeito:

Em Kierkegaard, não é através do pensamento que se apreende a existência, mas ao contrário, é na existência que se apreende o pensamento. Já em Rogers, o privilégio desvia-se do racional, para repousar na vivência do presente, o sentimento sobrepõe-se ao intelecto.

Outra questão significativa diz respeito ao discernimento de Rogers sobre a unidade de vivência entre terapeuta e cliente, esboçada anteriormente. Isso implica se opor à ideia de que a verdade advém de uma relação distanciada e objetiva do sujeito ante o objeto de conhecimento, tomando por pressuposto que estes se encontram em planos separados e distintos. A proposta de Rogers assume uma unidade entre esses termos, de modo que o conhecimento surge da relação singular estabelecida entre eles. A partir destas reflexões, traçaremos outro alinhamento epistemológico entre a ACP e a filosofia kierkegaardiana.

Rollo May (1993) entende que a não cisão entre sujeito e objeto se dá quando há implicação significativa do indivíduo com a existência. Kierkegaard avança nessa compreensão ao distinguir as possibilidades de conhecimento objetivo e subjetivo, considerando que o sujeito se apropria subjetivamente da verdade, mesmo quando se defronta com o que não é verdadeiro, a partir da relação apaixonada que estabelece consigo e com a existência (Kierkegaard, 1992). Nessa direção, Reichmann (1971, p. 220), 
tratando da filosofia kierkegaardiana, assinala: "a ciência quer nos ensinar que o caminho a seguir é o de tornar-se objetivo, enquanto que o cristianismo nos ensina que o caminho a seguir é o de tornar-se subjetivo, isto é, de tornar-se verdadeiramente um sujeito".

Sobre esse tema, é interessante a distinção que Kierkegaard faz entre o pagão que ora apaixonadamente para o ídolo e o cristão que reza falsamente para Deus. Apesar de o cristão ter uma compreensão correta de Deus, o pagão estaria mais próximo da verdade e, não obstante adorar um ídolo, relacionar-se-ia verdadeiramente com Deus. A seguinte passagem de Giles (1975, p. 10) ajuda a compreender essa distinção:

A verdade deve tornar-se existencial no ato do Indivíduo viver aquilo em que acredita na realização leal dos seus objetivos mais profundos. Portanto, o que é indispensável não é tanto conhecer a verdade e, sim, introduzi-la na existência. Em outras palavras, cada Indivíduo deve viver em função de uma idéia concreta que seja para ele o ideal de uma existência vivida.

A partir do entendimento desse desdobramento epistemológico do pensamento de Kierkegaard, é possível situar a intenção de Rogers de não objetificar o cliente, bem como de não compreendê-lo em termos de categorias pré-concebidas (Rogers \& Stevens, 1976). Intenta-se uma relação significativa, na qual a unidade de vivência entre terapeuta e cliente se produzirá. Essa unidade pode ser observada no seguinte excerto:

quando sou capaz de relaxar e de ficar próximo do meu âmago transcendental, comporto-me de um modo estranho e impulsivo na relação, que não posso justificar racionalmente e que não tem nada a haver (sic) com meus processos de pensamento [...] parece que meu espírito alcançou e tocou o espírito interno do outro. Nossa relação transcende a si mesma e se torna parte de algo maior (Rogers et al., 1983, p. 47).

O importante nessa unidade é que o conhecimento encontre seu parâmetro de validade na existência concreta dos indivíduos ali colocados, e não a partir de critérios objetivos ou de universalidade.
Exemplo disso é o caso de Ellen West, descrito por Binswanger (1977) e comentado por Rogers (Rogers \& Rosenberg, 1986). O criador da ACP compreendia que não interessava o diagnóstico atribuído àquela paciente, pois, segundo seu referencial, o importante seria o estabelecimento de uma relação significativa com Ellen. Nesta relação, ela "descobriria que sua própria experiência, desde que se abrisse a ela, desde que pudesse cuidadosamente ouvir o seu significado, forneceria uma orientação construtiva para seu comportamento" (Rogers \& Rosenberg, 1986, p. 100).

Assim, o modo como Rogers descreve a relação entre terapeuta e cliente evidencia a necessidade de aproximação e abertura. Estabelece-se um contraponto à cisão entre sujeito e objeto como pressuposto para a validação de um conhecimento e afirma-se, portanto, uma unidade entre ambos.

Nos momentos da psicoterapia marcados pela unidade de vivência aqui debatida, a experiência é sempre descrita em sua processualidade. Implica daí outra característica importante a partir da qual se pode traçar outra convergência epistemológica entre Rogers e Kierkegaard, qual seja, a de que o saber não consegue operar totalizações na existência.

Énotórioque,naperspectivade Kierkegaard, há uma afirmação contínua de que a existência resiste a ser absorvida por categorias ideais, em sua oposição à filosofia hegeliana (Ewald, 2008). A existência é sempre descrita em termos de ambivalências e tortuosidades. Assim, afirma-se que o conhecimento especulativo abstrai a existência, distanciando-se da experiência enquanto tal.

Giles (1975, p. 14) afirma que a filosofia não consegue reconciliar as contradições da existência, reduzindo-as somente a uma realidade fictícia criada em termos racionais, pois "existir significa devir [...] passagem do idêntico ao outro, destruição das categorias do idêntico e do outro no esforço de interiorização constante, união e desunião do finito e do infinito, contato entre os dois que é [...] conflito".

Sartre ajuda a compreender essa discussão ao afirmar que Kierkegaard, em oposição a Hegel, foi talvez o primeiro pensador a marcar a ideia de que há uma relação incomensurável entre o saber e o real. Sartre (1987, p. 116) assinala:

Kierkegaard tem razão: a dor, a necessidade, a paixão, o sofrimento dos homens, são realidades brutas que não podem ser superadas 
ou modificadas pelo saber; é certo que seu subjetivismo religioso pode passar com razão pelo cúmulo do idealismo, mas em relação a Hegel ele marca um progresso em direção ao realismo, já que insiste, antes de tudo, na irredutibilidade de um certo real ao pensamento e no seu primado.

A partir de uma lógica de pensamento similar presente na ACP, pode-se compreender que o terapeuta que se posiciona como pessoa afirma a impossibilidade de uma totalização da experiência pelo saber. Tal posicionamento já se fazia presente no livro Terapia centrada no cliente, quando, no prefácio, é apresentada a ideia de que a terapia:

é um processo, uma coisa-em-si, uma experiência, uma relação, uma dinâmica [...] Este livro mostra] o nosso firme sentimento de que o processo terapêutico é rico em obscuridades, complexidades e sutilezas, e a nossa igualmente firme convicção de que a conclusão científica, a generalização, é fria, sem vida - e carente da plenitude da experiência (Rogers, 1974,p. 14-15).

Essas reflexões apontam para mais uma possível aproximação epistemológica entre a ACP e a filosofia de Kierkegaard. Diante da incomensurabilidade do saber sobre o real, pode-se deduzir a impossibilidade de se representar ou de corresponder à linguagem a experiência vivida no processo terapêutico. Rogers $(1961 / 2001$, p. 233) aponta: "No domínio dos sentimentos, porém, nunca aprendemos a atribuir símbolos à experiência com a preocupação do significado preciso".

O aspecto a que Rogers faz referência é por ele explicitamente apontado como elemento que aproxima seu pensamento ao do filósofo dinamarquês. Tal aproximação se dá a partir da noção kierkegaardiana de comunicação indireta (Turnbull, 2009). Rogers entende que as verdades oriundas das aprendizagens significativas (La Puente, 1978) que advêm das vivências experimentadas por terapeuta e cliente na psicoterapia não podem ser ensinadas. Pelo contrário, quanto mais se tentasse transmitir esse tipo de conteúdo, mais distante se estaria de uma verdade.

A partir dessa perspectiva, a verdade deve advir de maneira autoapropriada e experiencial. Rogers (1961/2001, p. 234), traçando um paralelo com a perspectiva de Kierkegaard, afirma que o filósofo "considera esta última forma de aprendizagem como a verdadeira subjetividade, acentuando que não pode haver nenhuma comunicação direta disso ou sobre isso". O que é possível fazer é criar condições para que esse tipo de aprendizagem ocorra.

Derivam dessas ideias o uso de pseudônimos por Kierkegaard e sua compreensão de uma dialética qualitativa, na qual está inserido um negativo que mantém sempre algo de inapreensível em relação à existência. Assim, "a antítese permanece, está presente na síntese. A incerteza permanece no cerne da própria fé" (Giles, 1975, p. 14). Dialética que exige que o indivíduo impulsione-se no seu autoconhecimento e na sua relação com a existência. Como decorrência, tem-se que

o existencial, o subjetivo, o individual, o espírito, não podem ser comunicados diretamente a outro, pelo fato de que toda a experiência está isolada dentro do indivíduo. O que comunica permanece em si mesmo e é necessário que aquele a quem se comunica permaneça também em si. Por isso [Kierkegaard] escreve não para revelar seu pensamento, mas para que os leitores conheçam a si mesmos (Zengo, 2009).

Apesar da divisão que se fez das características relativas ao terapeuta como uma pessoa que se relaciona com seu cliente, estas devem ser compreendidas na relação íntima que estabelecem umas com as outras. Tal separação teve sua funcionalidade explicativa, mas perdeu a inteireza que esses atributos carregam quando postos em devir, ou melhor, quando o fluxo que as carrega se faz. Para compreendê-las de forma genuína, seria necessário colocá-las em movimento e, como se tentou deixar claro, o distanciamento e a frieza de um entendimento intelectual não se prestariam a tanto.

\section{Consideraçóes finais}

Mostrar possíveis convergências epistemológicas entre a ACP e a filosofia de Sören Kierkegaard exigiu que se debatesse o modo como o conhecimento é discutido por Rogers ao longo de sua obra. Observou-se que Rogers, ao mesmo tempo em que desenvolve boa parte de seus construtos teóricos a partir de métodos científicos de investigação, valoriza a vivência da relação terapêutica como condição 
fundamental para o bom andamento dessa, instaurando um paradoxo na ACP.

Esse parodoxo é apresentado por Rogers a partir de duas funções que desempenha na compreensão do processo terapêutico. A primeira seria a do cientista, aquele interessado nas minúcias do funcionamento de uma relação terapêutica satisfatória. A segunda faceta de seu trabalho seria a de pessoa que se relaciona com o cliente não a partir de categorias, mas tendo como referência a vivência imediata do aqui-e-agora na relação terapêutica.

A relação marcada pela genuinidade do terapeuta - característica peculiar de todo o desenvolvimento da ACP -, segundo o que se discutiu neste trabalho, possibilita uma compreensão distinta daquela inaugurada pela ciência moderna. Prova disso se apresenta na medida em que o saber científico rechaça a subjetividade como via privilegiada de acesso a um conhecimento verdadeiro, enquanto o enfoque centrado na pessoa afirma sua primazia.

A filosofia de Kierkegaard se apresenta como uma possibilidade interessante de inteligibilidade epistemológica da forma de conhecer que privilegia a singularidade da aprendizagem significativa (Rogers, 1978). Entre as carcaterísticas que aproximam os pensamentos rogeriano e kierkegaardiano, pôde-se destacar: a relação direta com a experiência como forma legítima de conhecer; a não separação entre sujeito e objeto; a concepção de que a existência é processual e a consequente insuficiência da racionalidade na compreensão da totalidade dessa; além do entendimento de que o conhecimento possui uma idiosincrasia em sua produção, o que aponta para a impossibilidade de sua comunicação plena.

É importante ressaltar que não se trata de fundamentar o pensamento de Rogers nas ideias de Kierkegaard. Admite-se aqui a crítica de Figueiredo (1996), que afirma que a psicologia humanista não possui raízes no pensamento de Kierkegaard, apesar do contato que Rogers manteve com a obra desse filósofo. Por outro lado, reconhece-se que alguns aspectos do pensamento rogeriano podem dialogar com facetas importantes da filosofia kierkegaardiana.

A partir das questões apresentadas ao longo deste artigo, algumas indagações podem ser delineadas, merecendo investigação posterior. Destacam-se, por exemplo:

1) que implicações metodológicas, para o campo da investigação do processo psicoterapêutico, podem ser desenvolvidas a partir da interlocução entre Kierkegaard e Rogers?

2) como estabelecer um diálogo consistente entre a forma singular de produção do conhecimento aqui descrita e aquelas já consagradas pelo método científico na compreensão do processo terapêutico? Dito de outra forma, será possível um diálogo entre a pessoa e o cientista?

3) em Rogers, essas questões se apresentam como um paradoxo, mas o que pode ser pensado além da contradição?

\section{Referências}

Amatuzzi, M. M. (1989). O resgate da fala autêntica: Filosofia da psicoterapia e da educação. Campinas: Papirus.

Amatuzzi, M. M. (2001). Por uma psicologia humana. Campinas: Alínea.

Bachelard, G. (1971). A epistemologia. Rio de Janeiro: Edições 70.

Blanché, R. (1988). A epistemologia. Lisboa: Presença.

Binswanger, L. (1977). El caso de Ellen West: Estudio antropológico-clínico. In R. May, E. Angel \& H. F. Ellenberger (Ed.). Existencia. Nueva dimensión en psiquiatría y psicología (pp. 288-434). Madrid: Editorial Gredos.

Bombassaro, L. C. (1992). As fronteiras da epistemologia: Como se produz conhecimento. Petrópolis: Vozes.

Cavalcante Júnior, F. S., \& Sousa, A. F. (2008). Humanismo de funcionamento pleno. Campinas: Alínea.

Cury, V. E. Psicoterapia centrada na pessoa: Evolução das formulações sobre a relação terapeuta cliente. São Paulo, Dissertação Mestrado, Instituto de Psicologia da Universidade de São Paulo, São Paulo.

Evans, R. I. (1979). Carl Rogers: O homem e suas idéias. São Paulo: Martins Fontes.

Ewald, A. P. (2008). Fenomenologia e existencialismo: Articulando nexos, costurando sentidos. Estudos e Pesquisas em Psicologia, 8(2), 149-165.

Farago, F. (2006). Compreender Kierkegaard. Petrópolis: Vozes.

Figueiredo, L. C. M. (1992). A invenção do psicológico: Quatro séculos de subjetivação. São Paulo: Escuta; EDUC. 
Figueiredo, L. C. M. (1996). Matrizes do pensamento psicológico. Petrópolis: Vozes.

Figueiredo, L. C. M. (2004). Revistando as psicologias: Da epistemologia à ética das práticas e discursos psicológicos. Petrópolis: Vozes.

Fonseca, A. H. L da. (1998). Trabalhando o legado de Rogers: Sobre os fundamentos fenomenológicoexistenciais. Maceió: Pedang.

Gardiner, P. (2001). Kierkegaard. São Paulo: Loyola.

Giles, T. R. (1975). História do existencialismo e da fenomenologia. São Paulo: E. P. U.

Holanda, A. F. (1997). Diálogo e psicoterapia: Correlações entre Carl Rogers e Martin Buber. São Paulo: Lemos Editorial.

Kierkegaard, S. A. (1979). O desespero humano (doença até a morte). In Coleção os pensadores (pp. 187279). São Paulo: Abril Cultural. (Originalmente publicado em 1849).

Kierkegaard, S. A. (1995). Migalhas filosóficas ou um bocadinho de filosofia de João Clímacus. Petrópolis: Vozes. (Originalmente publicado em 1844).

Kierkegaard, S. A. (1992). Concluding unscientific postscript to philosophical fragments. Princeton: Princeton University Press.

La Puente, M. O ensino centrado no aluno: Renovação e crítica das teorias educacionais de Carl Rogers. São Paulo: Cortez \& Moraes.

Lima, A. de A. (2008). Diálogo entre Carl Rogers e Martin Buber. Revista da Abordagem Gestáltica, 14(2), 233-243.

May, R. (1993). A descoberta do ser. Rio de Janeiro: Rocco.

Moreira, V. (2007). De Carl Rogers a Merleau-Ponty: A pessoa mundana em psicoterapia. São Paulo: Annablume.

Moreira, V. (2009). A Gestalt-Terapia e a abordagem centrada na pessoa são enfoques fenomenológicos? Revista da Abordagem Gestáltica, 15(1), 3-12.

Reichmann, E. (1971). Soren Kierkegaard. Curitiba: Edições Jr.

Rogers, C. R. (1974). Terapia centrada no paciente. São Paulo: Martins Fontes.
Rogers, C. R. (1978). Liberdade para aprender. Belo Horizonte: Interlivros.

Rogers, C. R. (1980). Duas tendências divergentes. In R. May (Org.). Psicologia Existencial (pp. 97-106). Porto Alegre: Globo.

Rogers, C. R. (1994). A equação do processo terapêutico. In J. K. Wood. (Org.). Abordagem centrada na pessoa (pp. 95-122). Vitória: Ceciliano Abel de Almeida.

Rogers, C. R. (2001). Tornar-se pessoa. São Paulo: Martins Fontes. (Originalmente publicado em 1961).

Rogers, C. R., \& Coulson, W. R. (1973). O homem e a ciência do homem. Belo Horizonte: Interlivros.

Rogers, C. R., \& Kinget, G. M. (1977). Psicoterapia e relações humanas. Belo Horizonte: Interlivros.

Rogers, C. R., \& Rosenberg, R. L. (1986). A pessoa como centro. São Paulo: E. P. U.

Rogers, C. R., \& Stevens, B. (1976). De pessoa para pessoa: O problema de ser humano. São Paulo: Pioneiras.

Rogers, C. R., \& Wood, J. K. (1978). Teoria centrada no cliente. In A. Burton. Teorias operacionais da personalidade (pp. 192-233). Rio de Janeiro: Imago.

Rogers, C. R., Wood, J. K., O'hara, M. M., \& Fonseca, A. H. L. da (1983). Em busca de vida: Da terapia centrada no cliente à abordagem centrada na pessoa. São Paulo: Summus.

Santos, B. de S. (1988). Um discurso sobre as ciências na transição para uma ciência pós-moderna. Estudos Avançados, 2(2), 46-71.

Sartre, J. P. (1979). O existencialismo é um humanismo. In Coleção Os pensadores (pp. 1-32). São Paulo: Abril Cultural.

Turnbull, J. (2009). Kierkegaard, indirect communication, and ambiguity. The Heythrop Journal, 50(1), 13-22.

Zengo, Z. A. Ética e existência em Kierkegaard. Recuperado em 25 jun. 2009, em http:/ / www.zzengo. hpg.ig.com.br/Kierkeg1.htm.

Recebido: 02/02/2010

Received: 02/02/2010

Aprovado: 19/05/2010

Approved: 05/19/2010 